\title{
Locus of the effect of a distinguishing feature in a memory search task
}

\author{
RODERICK W. BARRON \\ University of Guelph, Guelph, Ontario, Canada N1G $2 W 1$
}

\begin{abstract}
Subjects memorized one to four 8- or 16-sided random forms in a memory search task. The positive set forms ("yes" response) differed in number of sides from the negative set forms ("no" response) for the different set (DS) group, but this distinguishing feature was not available to the same set (SS) group. Mean reaction time increased as a linear function of $\log _{2}$ of the positive set size for both groups, but the increase was greater for the SS than the DS group, suggesting that memory search rather than an encoding stage of information processing was influenced by the availability of a distinguishing feature. In a transfer task which followed, new forms were introduced in which the positive and negative set forms differed in number of sides for both groups. In this task, the two groups did not differ in memory search, but in encoding. It was proposed that (a) availability of a distinguishing feature influences search time because the information specifying the number of sides of the set of memorized forms can be used to influence the speed with which individual forms are examined in memory; (b) previous experience with a distinguishing feature influences encoding because the DS group had learned to extract the information specifying the set of memorized forms (not the information specifying individual forms) more efficiently than the SS group.
\end{abstract}

Gibson (1969) proposed that economical strategies for processing information can be acquired in visual and memory search tasks when the target and nontarget items can be consistently distinguished on the basis of a single feature. This was demonstrated by Yonas and Gibson (1967) in a memory search task in which an ensemble of nine letters $(A, O, F, N, V, E, C, H, B)$ was employed. In the first condition of their experiment, a diagonal line was present in all of the target letters $(A, N, V)$ memorized by the subjects (positive set), but it was not present in any of the nontarget (negative set) letters $(\mathrm{O}, \mathrm{F}, \mathrm{E}, \mathrm{C}, \mathrm{H}, \mathrm{B})$. In the second condition, letters were chosen which minimized the possibility of distinguishing the positive set letters $(\mathrm{A}, \mathrm{O}, \mathrm{F})$ from the negative set letters $(N, V, E, C, H, B)$ on the basis of a single distinguishing feature. A single letter (E) was used as the positive set in the third condition, with the remaining letters in the ensemble making up the negative set. After 1 day of practice (135 trials per condition), the mean reaction time (RT) was almost identical for the two multiple letter conditions (ANV, AOF), but both of these conditions were slower than the single letter condition (E). Following 35 days of practice by one heroic subject, however, the RT for the ANV condition equalled that for $\mathrm{E}$, whereas the AOF condition was the slowest. Yonas and Gibson (1967) interpreted their results as evidence that an optimal strategy had been

This report is based upon a dissertation submitted to The Ohio State University in partial fulfillment of the requirements for the Ph.D. degree. The author is indebted to Dean $H$. Owen, chairman of his dissertation committee, for his encouragement, guidance, and constructive criticisms throughout all phases of this study. This investigation was supported by an NSF Trainseeship awarded to the author through The Ohio State University Graduate School. The comments of Ernest Dalrymple-Alford, Arthur Johnsen, Yvette and Richard Tenney, John Pittenger and Jennifer Ruff on an earlier version of this manuscript are gratefully acknowledged.

Department of Psychology, University of Guelph, Guelph, Ontario, Canada, N1G 2 W1. learned which reduced the information processed to a minimum distinguishing feature.

Sternberg (1969) has argued that RT can be partitioned into separate, additive components in a variety of tasks. In a memory search task, for example, Sternberg obtained a linear relationship between RT and positive set size (M) and he expressed the relationship as

$$
R T=a+b(M) .
$$

Other investigators (Ross, 1970; Simpson, 1972; Swanson \& Briggs, 1969) have obtained log rather than linear relationships. Swanson and Briggs (1969) expressed the log relationship they obtained between RT and positive set size as

$$
\mathrm{RT}=\mathrm{a}+\mathrm{b}(\mathrm{Hc}),
$$

where $\mathrm{Hc}$ refers to central processing uncertainty and is primarily determined by positive set size.

Regardless of whether M or Hc is used, the successive operations of encoding, memory search, and response selection have been proposed to occupy the time between test item presentation and response execution. The intercepts (a) of Equations 1 and 2 are interpreted as consisting of the combined times of the first (encoding) and third (response selection) operations. The slopes (b) are interpreted as the amount of time occupied by the second operation (memory search) and can be considered as the amount of time per unit of testing $(\mathrm{M}$ or $\mathrm{Hc})$ to decide whether or not a test item is a member of the positive set.

One advantage of the memory search task is that it is possible to specify the locus of the influence of a variable or factor upon one or more operations or stages 
of information processing (Sternberg, 1969). Although Yonas and Gibson (1967) used a memory search task, they did not vary positive set size and availability of a distinguishing feature orthogonally; therefore it is not possible to localize the stage or stages of processing which may have been influenced by these two factors. Applying the logic of Sternberg's (1969) additive factor method to a memory search task, positive set size and availability of a distinguishing feature were varied orthogonally in Part 1 of the present experiment. Availability of a distinguishing feature depended on whether or not the positive set forms (Attneave \& Arnoult, 1956) differed in number of sides from the negative set forms. Accordingly, subjects in the different set condition (DS) group were given 8-sided positive set forms and 16-sided negative set forms, or vice versa. Subjects in the same set group condition (SS group), were given only 8 -sided or only 16 -sided forms in the two sets. If availability of a distinguishing feature influences the duration of test stimulus encoding or response selection, then the intercepts of the two groups should differ, but not their slopes. If, on the other hand, the rate of memory search is influenced by the availability of a distinguishing feature, then the slopes of the two groups should differ, but not their intercepts.

A forced-choice recognition test was used in Part 2 to determine if the two groups were using different information processing strategies. If subjects in the DS group can use information specifying number of sides to determine the set membership of a random form, then it may be that they will ignore the nonessential details of individual forms, particularily in the negative set. Such a strategy may result in a reduction in RT, but it may also impair their ability to recognize subsequently members of the negative set when compared to the SS group.

A transfer task was introduced in Part 3 to investigate further the possibility that subjects in the SS and DS groups may have used different strategies for processing information. Yonas (1969) found that practice in using curvature to distinguish positive $(\mathrm{O}, \mathrm{S}, \mathrm{G})$ from negative set $(E, Z, A)$ letters facilitated performance when new letters were introduced in a transfer task because curvature was again available for distinguishing the positive $(Q, C, R)$ from the negative $(N, F, V)$ sets. The curvature group was faster than groups having the same amount of prior practice with a different distinguishing feature or with no distinguishing feature. Accordingly, new random forms were introduced in Part 3 of the present experiment. The major difference from Part 1 was that the positive set forms differed in number of sides from the negative set forms for both the SS and DS groups. If subjects in the DS group have learned a more efficient strategy for processing information as a result of their experience with a distinguishing feature in Part 1, then they should be faster than the SS group even though the information available to both groups is identical. Furthermore, it may be possible to specify the locus of any transfer effects in terms of one or more stages of information processing.

\section{METHOD}

\section{Subjects}

Thirty-two males served as subjects. They responded to advertisements distributed on the Ohio State University campus and were paid for their participation.

\section{Stimulus materials}

A total of 448 random forms were used in the three parts of this experiment. They were constructed according to Attneave and Arnoult's (1956) Method I rules for randomly derived straight-sided closed polygons, and equated for area. The forms were randomly assigned to the three parts of the experiment with the constraint that an equal number of 8 - and 16-sided forms were used in each part. One hundred and seventy-six forms were used in Part 1 (training), 96 in Part 2 (forced-choice recognition), and 176 in Part 3 (transfer).

\section{Construction of the positive and negative sets}

Four positive sets of 8-sided forms and four positive sets of 16-sided forms were randomly selected from the 176 Part 1 forms in order to reduce the possibility of obtaining results which were specific to a particular set of forms. The 10 forms making up each positive set were divided into positive set sizes of one, two, three, and four forms. The remaining 96 Part 1 forms made up the two negative sets. One negative set had 48, 8-sided forms and the other had 48, 16-sided forms.

Sixteen subjects were used in the same set (SS) group and 16 in the different set (DS) group. Eight of the subjects in the SS group had 8-sided forms in both the positive and negative sets, while the other eight subjects had 16-sided forms in both sets. The sets of forms used by the DS group were identical to those used by the SS group. The only difference between the two groups was that the forms assigned to the positive sets differed in number of sides from the forms assigned to the negative sets for the DS group. Eight subjects in the DS group had 8-sided positive set forms and 16-sided negative set forms, while the other eight subjects in the DS group had 16-sided positive set forms and 8-sided negative set forms. The Part 1 conditions are presented in Table 1.

Nonoverlapping positive and negative sets were used in both groups. A form which appeared in a positive set never appeared in a negative set and vice versa. Furthermore, each positive set form was permanently assigned to only one positive set size. In order to avoid the possibility that a particular negative set form

Table 1

Number of Sides of the Forms Appearing in the Positive and Negative Sets in Parts 1 and 3

\begin{tabular}{|c|c|c|c|c|}
\hline & \multicolumn{2}{|c|}{ Part 1} & \multicolumn{2}{|c|}{ Part 3} \\
\hline & $\begin{array}{c}\text { Positive } \\
\text { Set }\end{array}$ & $\begin{array}{c}\text { Negative } \\
\text { Set }\end{array}$ & $\begin{array}{c}\text { Positive } \\
\text { Set }\end{array}$ & $\begin{array}{c}\text { Negative } \\
\text { Set }\end{array}$ \\
\hline \multirow{2}{*}{ Group SS } & 8 & 8 & $\begin{array}{r}8 \\
16\end{array}$ & $\begin{array}{r}16 \\
8\end{array}$ \\
\hline & 16 & 16 & $\begin{array}{r}8 \\
16\end{array}$ & $\begin{array}{r}16 \\
8\end{array}$ \\
\hline \multirow{2}{*}{ Group DS } & 8 & 16 & $\begin{array}{r}8 \\
16\end{array}$ & $\begin{array}{r}16 \\
8\end{array}$ \\
\hline & 16 & 8 & $\begin{array}{r}8 \\
16\end{array}$ & $\begin{array}{r}16 \\
8\end{array}$ \\
\hline
\end{tabular}


would become associated with one of the positive set sizes, each negative set form appeared equally often with each of the positive set sizes across blocks of trials.

\section{Procedure and apparatus}

The following sequence of events took place on each trial. The form or forms making up a particular positive set size were back projected onto a translucent screen with a Kodak projector (RA950). The forms were simultaneously presented side by side and appeared as black outlines against a light background. These forms were displayed before each trial providing the subjects with ample time to study and memorize them. Removal of the forms from the screen signaled that a test form would be displayed when the subject pressed a foot pedal which opened a shutter in front of a second projector. A millisecond timer (Hewlett-Packard 5221B electronic counter) started simultaneously with the opening of the shutter. The subject responded "yes" if the test item was a member of the positive set by moving a lever in a specified direction (left or right). If the test item was not a member of the positive set, he responded "no" by moving the lever in the opposite direction. A correct response stopped the timer and closed the shutter, but an incorrect response only stopped the timer, leaving the shutter open until a correct response was made. The probabilities of the yes and no responses were equal, and the direction of the lever movement (left or right) for yes and no responses was counterbalanced across subjects. A subject was seated $92 \mathrm{~cm}$ from the screen, and the visual angle of the largest test item was $4.7 \mathrm{deg}$. The subjects were instructed to respond as quickly as possible without sacrificing their accuracy.

Each subject received eight blocks of trials, two blocks per day with a brief rest period between. blocks. Each block consisted of 96 problems divided into four sessions of 24 problems each (12 problems required a yes response and 12 problems required a no response). All four sizes of the positive set were presented within a block, but only one positive set size was presented within a session. Each positive set size appeared equally often within each of the four sessions across the eight blocks. The problems were presented in random order within a session with the constraint that no more than four responses of the same type (yes or no) could appear in succession.

\section{Forced-choice recognition task}

Twenty-four hours after the last block of Part 1 the subjects were given a forced-choice recognition memory task (Shepard, 1967). Each of the 48 negative set forms ("old" form) was paired with a "new" form the subjects liad never seen, but which had the same number of sides as the old form. Each pair of forms was presented simultaneously, and the subjects were instructed to move a lever to the left or right toward the old form. The old form appeared equally often on the left and the right, and the pairs were presented randomly with the constraint that there be no more than four consecutive presentations of the old form on the left or right. The subjects were not under any time pressure to respond in Part 2, although their latencies were recorded, and they were instructed to be as accurate as possible. Following each judgment, the subjects rated their confidence in their judgment on a five-point scale. The subjects were not informed that they would be required to remember the negative set forms prior to the recognition task.

\section{Transfer task}

The transfer conditions are also presented in Table 1. On the day following Part 2 (forced-choice recognition), subjects in the SS and DS groups were assigned new forms. The forms assigned to the positive sets had a different number of sides ( 8 or 16 sides) than the forms assigned to the negative sets (16 or 8 sides) for all subjects in both groups. The construction of the positive and negative sets, the task, the procedure, and the design in Part 3 were identical to Part 1 except that four rather than eight blocks of trials were used and these four blocks were completed within a single day with a short rest between blocks.

\section{Pre-experimental letter recognition task}

Before Part 1 of the experiment actually began, subjects participated in a task designed to acquaint them with the apparatus and procedure. In addition, an individual subject's RT in this task was used as a basis for assignment to the SS or DS groups in order to equate the two groups as closely as possible in RT prior to Part 1. The procedure was identical to Parts 1 and 3 except that letters were used (Para-Type 18-point Futura Medium uppercase), two blocks of practice were employed, and the positive set sizes appeared in the same order for all subjects. The letter $G$ was used for positive set size one; $Z$ and $J$ for two; $B, W$, and $L$ for three; and $H, S, X$, and $F$ for four. The letters $A$, $\mathrm{C}, \mathrm{D}, \mathrm{E}, \mathrm{P}, \mathrm{I}, \mathrm{K}, \mathrm{N}, \mathrm{O}, \mathrm{R}, \mathrm{T}$, and $\mathrm{U}$ made up the negative set.

\section{RESULTS}

\section{Pre-experimental letter recognition task}

Following the assignment of subjects to the SS and DS groups on the basis of their mean RT in the letter recognition task, analyses of variance were conducted on the mean RTs and error frequencies for each subject at each of the levels of the positive set size (one to four), response (yes, no), and blocks (two) factors. There were no significant main effects or interactions involving the groups factor in either analysis $(p>10)$. The results indicate that the SS and DS groups were similar in RT prior to the beginning of Part 1 .

\section{Part 1-Training}

Latencies for correct responses were used in calculating mean RTs for each subject at each of the levels of the positive set size (one to four), response (yes, no), and blocks (one to eight) factors. Error free performance resulted in a mean RT based on 12 latencies. A 2 (groups) by 4 (positive set size) by 2 (response) by 8 (blocks) analysis of variance on the mean RTs indicated that all main effects were significant $(p<.001)$. The following first order interactions were also significant: Groups by Positive Set Size $(F(3,90)=7.56, p<.001)$; Blocks by Positive Set Size $F(21,630)=9.19, \quad p<.001 ; \quad$ Response by Groups $F(1,30)=5.89, p<.025$; and Response by Blocks $F(7,210)=10.25 ; p<.001$. The remaining first order interactions were nonsignificant $(p>.05)$, and none of the second and third order interactions were significant $(p>.10)$. Mean reaction times and error percentages for all four factors are presented in Table 2.

The Groups by Positive Set Size interaction is presented in Figure 1. Examination of that figure shows that RT was a linear function of $\log _{2}$ of positive set size for both groups. Accordingly, $\mathrm{Hc}$, the measure of central processing uncertainty developed by Briggs (1972) and his colleagues (e.g., Briggs \& Johnsen, 1973; Swanson \& Briggs, 1970) was used as the basic predictor variable 
Table 2

Mean Reaction Time (RT) in Milliseconds and Percent Error for Each of the Experimental Conditions in Part 1

\begin{tabular}{|c|c|c|c|c|c|c|c|c|c|c|c|c|c|c|c|c|c|}
\hline \multirow{3}{*}{$\begin{array}{c}\text { Positive } \\
\text { Set } \\
\text { Size }\end{array}$} & & \multicolumn{4}{|c|}{ Block 1} & \multicolumn{4}{|c|}{ Block 2} & \multicolumn{4}{|c|}{ Block 3} & \multicolumn{4}{|c|}{ Block 4} \\
\hline & & \multicolumn{2}{|c|}{ SS } & \multicolumn{2}{|c|}{ DS } & \multicolumn{2}{|c|}{ SS } & \multicolumn{2}{|c|}{ DS } & \multicolumn{2}{|c|}{ SS } & \multicolumn{2}{|c|}{ DS } & \multicolumn{2}{|c|}{ SS } & \multicolumn{2}{|c|}{ DS } \\
\hline & & Yes & No & Yes & No & Yes & No & Yes & No & Yes & No & Yes & No & Yes & No & Yes & No \\
\hline 1 & $\begin{array}{l}\text { RT } \\
\text { Percent }\end{array}$ & $\begin{array}{l}582 \\
0.52\end{array}$ & $\begin{array}{l}603 \\
1.04\end{array}$ & $\begin{array}{l}528 \\
1.56\end{array}$ & $\begin{array}{l}526 \\
1.56\end{array}$ & $\begin{array}{l}494 \\
1.56\end{array}$ & $\begin{array}{l}549 \\
1.04\end{array}$ & $\begin{array}{l}432 \\
0.00\end{array}$ & $\begin{array}{l}458 \\
2.08\end{array}$ & $\begin{array}{l}461 \\
3.13\end{array}$ & $\begin{array}{l}505 \\
0.52\end{array}$ & $\begin{array}{l}417 \\
1.56\end{array}$ & $\begin{array}{l}439 \\
2.08\end{array}$ & $\begin{array}{l}430 \\
1.56\end{array}$ & $\begin{array}{l}473 \\
0.00\end{array}$ & $\begin{array}{l}414 \\
3.65\end{array}$ & $\begin{array}{l}432 \\
1.56\end{array}$ \\
\hline 2 & $\begin{array}{l}\text { RT } \\
\text { Percent }\end{array}$ & $\begin{array}{l}768 \\
1.56\end{array}$ & $\begin{array}{l}769 \\
3.13\end{array}$ & $\begin{array}{l}634 \\
5.73\end{array}$ & $\begin{array}{l}625 \\
2.08\end{array}$ & $\begin{array}{l}610 \\
1.04\end{array}$ & $\begin{array}{l}630 \\
1.04\end{array}$ & $\begin{array}{l}518 \\
5.21\end{array}$ & $\begin{array}{l}526 \\
2.08\end{array}$ & $\begin{array}{l}551 \\
4.69\end{array}$ & $\begin{array}{l}566 \\
2.60\end{array}$ & $\begin{array}{l}475 \\
4.17\end{array}$ & $\begin{array}{l}493 \\
2.60\end{array}$ & $\begin{array}{l}483 \\
3.65\end{array}$ & $\begin{array}{l}528 \\
3.13\end{array}$ & $\begin{array}{l}449 \\
3.65\end{array}$ & $\begin{array}{l}472 \\
2.08\end{array}$ \\
\hline 3 & $\begin{array}{l}\text { RT } \\
\text { Percent }\end{array}$ & $\begin{array}{l}827 \\
3.65\end{array}$ & $\begin{array}{l}810 \\
1.56\end{array}$ & $\begin{array}{l}690 \\
4.69\end{array}$ & $\begin{array}{l}644 \\
2.08\end{array}$ & $\begin{array}{l}645 \\
3.13\end{array}$ & $\begin{array}{l}668 \\
2.08\end{array}$ & $\begin{array}{l}543 \\
2.60\end{array}$ & $\begin{array}{l}548 \\
1.56\end{array}$ & $\begin{array}{l}569 \\
1.56\end{array}$ & $\begin{array}{l}588 \\
2.08\end{array}$ & $\begin{array}{l}488 \\
3.13\end{array}$ & $\begin{array}{l}503 \\
2.60\end{array}$ & $\begin{array}{l}517 \\
1.04\end{array}$ & $\begin{array}{l}563 \\
4.17\end{array}$ & $\begin{array}{l}452 \\
3.65\end{array}$ & $\begin{array}{l}487 \\
1.04\end{array}$ \\
\hline \multirow[t]{2}{*}{4} & $\begin{array}{l}\text { RT } \\
\text { Percent }\end{array}$ & $\begin{array}{l}950 \\
7.81\end{array}$ & $\begin{array}{l}944 \\
2.08\end{array}$ & $\begin{array}{l}750 \\
7.29\end{array}$ & $\begin{array}{l}695 \\
1.04\end{array}$ & $\begin{array}{l}658 \\
4.17\end{array}$ & $\begin{array}{l}700 \\
1.04\end{array}$ & $\begin{array}{l}536 \\
5.21\end{array}$ & $\begin{array}{l}558 \\
2.08\end{array}$ & $\begin{array}{l}597 \\
3.65\end{array}$ & $\begin{array}{l}639 \\
2.08\end{array}$ & $\begin{array}{l}507 \\
1.04\end{array}$ & $\begin{array}{l}521 \\
3.65\end{array}$ & $\begin{array}{l}544 \\
3.65\end{array}$ & $\begin{array}{l}588 \\
6.77\end{array}$ & $\begin{array}{l}479 \\
3.65\end{array}$ & $\begin{array}{l}501 \\
5.21\end{array}$ \\
\hline & & \multicolumn{4}{|c|}{ Block 5} & \multicolumn{4}{|c|}{ Block 6} & \multicolumn{4}{|c|}{ Block 7} & \multicolumn{4}{|c|}{ Block 8} \\
\hline 1 & $\begin{array}{l}\text { RT } \\
\text { Percent }\end{array}$ & $\begin{array}{l}412 \\
2.08\end{array}$ & $\begin{array}{l}472 \\
3.13\end{array}$ & $\begin{array}{l}390 \\
3.13\end{array}$ & $\begin{array}{l}416 \\
2.60\end{array}$ & $\begin{array}{l}423 \\
1.04\end{array}$ & $\begin{array}{l}469 \\
1.56\end{array}$ & $\begin{array}{l}378 \\
2.08\end{array}$ & $\begin{array}{l}414 \\
3.13\end{array}$ & $\begin{array}{l}412 \\
1.04\end{array}$ & $\begin{array}{l}470 \\
2.08\end{array}$ & $\begin{array}{l}380 \\
1.04\end{array}$ & $\begin{array}{l}410 \\
3.65\end{array}$ & $\begin{array}{l}403 \\
2.60\end{array}$ & $\begin{array}{l}454 \\
2.60\end{array}$ & $\begin{array}{l}385 \\
4.17\end{array}$ & $\begin{array}{l}409 \\
2.60\end{array}$ \\
\hline 2 & $\begin{array}{l}\text { RT } \\
\text { Percent }\end{array}$ & $\begin{array}{l}487 \\
3.65\end{array}$ & $\begin{array}{l}515 \\
3.13\end{array}$ & $\begin{array}{l}441 \\
3.13\end{array}$ & $\begin{array}{l}459 \\
2.60\end{array}$ & $\begin{array}{l}489 \\
4.17\end{array}$ & $\begin{array}{l}539 \\
1.56\end{array}$ & $\begin{array}{l}429 \\
7.29\end{array}$ & $\begin{array}{l}447 \\
2.60\end{array}$ & $\begin{array}{l}468 \\
3.65\end{array}$ & $\begin{array}{l}516 \\
3.13\end{array}$ & $\begin{array}{l}408 \\
4.17\end{array}$ & $\begin{array}{l}428 \\
3.13\end{array}$ & $\begin{array}{l}463 \\
3.13\end{array}$ & $\begin{array}{l}506 \\
3.65\end{array}$ & $\begin{array}{l}410 \\
3.13\end{array}$ & $\begin{array}{l}442 \\
4.69\end{array}$ \\
\hline 3 & $\begin{array}{l}\text { RT } \\
\text { Percent }\end{array}$ & $\begin{array}{l}497 \\
5.21\end{array}$ & $\begin{array}{l}534 \\
4.17\end{array}$ & $\begin{array}{l}441 \\
3.13\end{array}$ & $\begin{array}{l}474 \\
2.08\end{array}$ & $\begin{array}{l}502 \\
1.04\end{array}$ & $\begin{array}{l}539 \\
2.60\end{array}$ & $\begin{array}{l}420 \\
2.08\end{array}$ & $\begin{array}{l}459 \\
1.56\end{array}$ & $\begin{array}{l}503 \\
3.13\end{array}$ & $\begin{array}{l}549 \\
1.56\end{array}$ & $\begin{array}{l}423 \\
3.13\end{array}$ & $\begin{array}{l}438 \\
2.60\end{array}$ & $\begin{array}{l}488 \\
2.60\end{array}$ & $\begin{array}{l}523 \\
3.65\end{array}$ & $\begin{array}{l}440 \\
4.17\end{array}$ & $\begin{array}{l}460 \\
1.56\end{array}$ \\
\hline 4 & $\begin{array}{l}\text { RT } \\
\text { Percent } \\
\end{array}$ & $\begin{array}{l}517 \\
3.65 \\
\end{array}$ & $\begin{array}{l}559 \\
4.69 \\
\end{array}$ & $\begin{array}{l}469 \\
3.13 \\
\end{array}$ & $\begin{array}{l}495 \\
2.60 \\
\end{array}$ & $\begin{array}{l}534 \\
3.13 \\
\end{array}$ & $\begin{array}{l}556 \\
3.13 \\
\end{array}$ & $\begin{array}{l}444 \\
3.65 \\
\end{array}$ & $\begin{array}{l}463 \\
2.60 \\
\end{array}$ & $\begin{array}{l}510 \\
3.13 \\
\end{array}$ & $\begin{array}{l}562 \\
2.60 \\
\end{array}$ & $\begin{array}{l}440 \\
6.22 \\
\end{array}$ & $\begin{array}{l}471 \\
3.65\end{array}$ & $\begin{array}{l}495 \\
1.56\end{array}$ & $\begin{array}{l}562 \\
5.73 \\
\end{array}$ & $\begin{array}{l}442 \\
2.60 \\
\end{array}$ & $\begin{array}{l}458 \\
1.56 \\
\end{array}$ \\
\hline
\end{tabular}

rather than M (Sternberg, 1966) in the statement of additivity in RT.' Further, examination of Figure 1 shows that RT increased with positive set size and that the amount of this increase was greater for the SS than the DS group. The yes and no responses were combined because their slopes did not differ in either the SS or DS groups, $\mathrm{t}(124)=.33, .48$, respectively; $p>.10$ in both cases. Finally, the best-fit linear equations shown in Figure 1 indicate that the availability of a distinguishing feature influenced the slope (b), but not the intercept (a) of the RT $=a+b(\mathrm{Hc})$ function. The 6-msec intercept difference between the two groups was not significant, $t(124)=.50, p>.10$ (Draper \& Smith, 1969).

The overall error rate was $2.93 \%$. An analysis of variance on the frequency of errors indicated that there were not any significant main effects or interactions involving the groups factor $(p>.10)$. As shown in Figure 1, the similarity of the error rates between the SS and DS groups across positive set size suggests that the lower RT obtained by the DS group was not due to subjects sacrificing their accuracy in order to increase their speed.

The Blocks by Positive Set Size interaction was further analyzed by obtaining intercept and slope values for each subject for each of the eight blocks of practice (yes and no responses were combined). These values were entered into separate one-way analyses of variance on the blocks factor, one for intercept and one for slope values. Significant effects were obtained for the slope values $F(7,217)=18.73, p<.001$, but not for the intercept values, $F(7,217)=1.083, p>.10$. As shown in Table 3, decreasing slope, not intercept values over blocks of practice were responsible for the Blocks by
Positive Set Size interaction.

The two remaining interactions both involved the response factor. The Response by Groups interaction suggested that the availability of a distinguishing feature influenced the speed with which a no response was

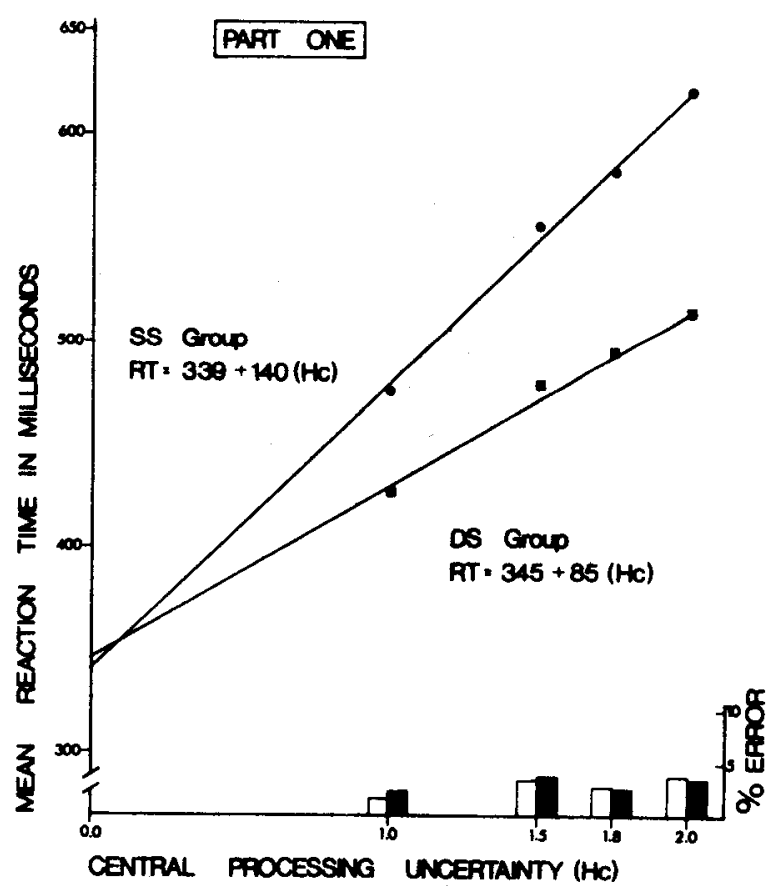

Figure 1. Best fit linear equations using Hc (measured in bits) as the predictor variable and percent errors for the SS and DS groups in Part 1 (training). Error percentage is indicated by the empty columns for the SS group and by the filled columns for the DS group. The yes and no responses are combined. 
Table 3

Intercept and Slope Values (in Milliseconds) Across Blocks of Practice in Parts 1 and 3

\begin{tabular}{|c|c|c|c|c|c|c|c|c|c|c|c|c|}
\hline & \multicolumn{8}{|c|}{ Blocks: Part 1} & \multicolumn{4}{|c|}{ Blocks: Part 3} \\
\hline & 1 & 2 & 3 & 4 & 5 & 6 & 7 & 8 & 1 & 2 & 3 & 4 \\
\hline Intercept & 300 & 359 & 353 & 347 & 342 & 351 & 337 & 338 & 308 & 326 & 320 & 330 \\
\hline Slope & 260 & 132 & 106 & 90 & 84 & 75 & 79 & 77 & 115 & 86 & 82 & 78 \\
\hline
\end{tabular}

made. Although yes responses were faster than no responses for both groups, the no responses were executed $20 \mathrm{msec}$ faster in the DS condition. The best fit linear equations for the yes and no responses in the SS group were $\mathrm{RT}=310+146(\mathrm{Hc})$ and $\mathrm{RT}=366+133(\mathrm{Hc})$, respectively. For the DS group, they were RT $=328+91(\mathrm{Hc})$ for the yes responses and $360+81$ (IIc) for the no responses.

The Response by Blocks interaction revealed a shift in the relative speed of yes and no responses across blocks of practice. The no responses were $14 \mathrm{msec}$ faster than the yes responses in the first block of practice. In the second block, the yes responses were 26 msec faster than the no responses, and by the seventh block this difference had increased to a maximum of $38 \mathrm{msec}$.

\section{Part 2-Forced-Choice Recognition}

The SS group correctly recognized $77 \%$ and the DS group $74 \%$ of the negative set forms in the forced-choice recognition task. Although in the predicted direction, this difference was not significant, $\mathrm{t}(30)=.98, \mathrm{p}>.10$. The confidence ratings for correct recognitions were significantly higher for the SS than the DS group $t(30)=2.71, p<.02$, but significant differences were not obtained between the two groups in confidence ratings for incorrect recognitions or in latencies for correct and incorrect recognitions $(\mathrm{p}>.10)$.

\section{Part 3-Transfer}

Latencies for correct responses were again used in calculating mean RTs for each subject at each of the levels of the positive set size (one to four), response (yes, no) and blocks (one to four) factors. A 2 (groups) by 4 (positive set size) by 2 (response) by 4 (blocks) analysis on the mean RTs indicated that the positive set size, response, and blocks main effects were' all significant $(p<.001)$. In addition, the groups main effect was significant, $F(1,30)=5.06, p<.05$, with the DS group being $33 \mathrm{msec}$ faster than the SS group, indicating a transfer effect. Contrary to the results of Part 1, a Groups by Positive Set Size interaction was not obtained, $F(3,90)=.62, p>.10$. The Blocks by Positive Set Size $F(9,270)=2.71, p<.01$, and Response by Blocks $F(3,90)=6.59, p<.001$, first order interactions were again significant, but the remaining first order interactions were not $(p>.05)$, nor were any of the higher order interactions $(p>.10)$. The mean reaction times and error percentages for all four factors are presented in Table 4.

Figure 2 shows that RT was again a linear function of $\log _{2}$ of the positive set size for both groups. Since the groups main effect was significant, but the Groups by Positive Set Size interaction was not, parallel lines were fit to the SS and DS groups using $\mathrm{Hc}$ as the predictor variable. The yes and no responses were again combined because their slopes (derived from best fit linear equations) did not differ for either the SS or DS groups, $\mathrm{t}(124)=.40, .43$, respectively; $\mathrm{p}>.10$ in both cases. Figure 2 also shows that only the intercepts differed when a distinguishing feature was made available to both groups, $\mathrm{t}(124)=3.50, \mathrm{p}<.001$. The DS group's experience with a distinguishing feature in Part 1 was useful in reducing $\mathrm{RT}$ in transfer (Part 3) relative to the SS group, even though both groups received identical positive and negative set forms in Part 3.

The overall error rate in Part 3 was $3.31 \%$. An analysis of variance on the frequency of errors indicated that there were not any significant main effects or

Table 4

Mean Reaction Time (RT) in Milliseconds and Percent Error for Each of the Experimental Conditions in Part 3

\begin{tabular}{|c|c|c|c|c|c|c|c|c|c|c|c|c|c|c|c|c|c|}
\hline \multirow{3}{*}{$\begin{array}{c}\text { Positive } \\
\text { Set } \\
\text { Size } \\
\end{array}$} & & \multicolumn{4}{|c|}{ Block 1} & \multicolumn{4}{|c|}{ Block 2} & \multicolumn{4}{|c|}{ Block 3} & \multicolumn{4}{|c|}{ Block 4} \\
\hline & & \multicolumn{2}{|c|}{ SS } & \multicolumn{2}{|c|}{ DS } & \multicolumn{2}{|c|}{ SS } & \multicolumn{2}{|c|}{ DS } & \multicolumn{2}{|c|}{ SS } & \multicolumn{2}{|c|}{ DS } & \multicolumn{2}{|c|}{ SS } & \multicolumn{2}{|c|}{ DS } \\
\hline & & Yes & No & Yes & No & Yes & No & Yes & No & Yes & No & Yes & No & Yes & No & Yes & No \\
\hline 1 & $\begin{array}{l}\text { RT } \\
\text { Percent }\end{array}$ & $\begin{array}{c}420 \\
.52\end{array}$ & $\begin{array}{l}470 \\
3.13\end{array}$ & $\begin{array}{c}396 \\
.52\end{array}$ & $\begin{array}{l}428 \\
3.13\end{array}$ & $\begin{array}{c}403 \\
.52\end{array}$ & $\begin{array}{l}444 \\
3.65\end{array}$ & $\begin{array}{l}385 \\
1.04\end{array}$ & $\begin{array}{l}409 \\
1.56\end{array}$ & $\begin{array}{l}393 \\
2.08\end{array}$ & $\begin{array}{l}434 \\
2.60\end{array}$ & $\begin{array}{l}367 \\
1.04\end{array}$ & $\begin{array}{c}401 \\
.52\end{array}$ & $\begin{array}{l}384 \\
2.60\end{array}$ & $\begin{array}{l}449 \\
3.65\end{array}$ & $\begin{array}{l}337 \\
1.04\end{array}$ & $\begin{array}{l}410 \\
2.60\end{array}$ \\
\hline 2 & $\begin{array}{l}\text { RT } \\
\text { Percent }\end{array}$ & $\begin{array}{l}468 \\
3.13\end{array}$ & $\begin{array}{l}497 \\
2.60\end{array}$ & $\begin{array}{l}450 \\
6.22\end{array}$ & $\begin{array}{l}458 \\
2.60\end{array}$ & $\begin{array}{l}443 \\
4.17\end{array}$ & $\begin{array}{l}491 \\
2.08\end{array}$ & $\begin{array}{c}444 \\
.52\end{array}$ & $\begin{array}{l}452 \\
1.56\end{array}$ & $\begin{array}{l}451 \\
4.17\end{array}$ & $\begin{array}{l}485 \\
1.04\end{array}$ & $\begin{array}{l}421 \\
2.60\end{array}$ & $\begin{array}{l}438 \\
2.60\end{array}$ & $\begin{array}{l}442 \\
3.13\end{array}$ & $\begin{array}{l}494 \\
2.60\end{array}$ & $\begin{array}{l}418 \\
3.13\end{array}$ & $\begin{array}{l}445 \\
2.08\end{array}$ \\
\hline 3 & $\begin{array}{l}\text { RT } \\
\text { Percent }\end{array}$ & $\begin{array}{l}516 \\
5.73\end{array}$ & $\begin{array}{c}543 \\
.00\end{array}$ & $\begin{array}{l}504 \\
6.77\end{array}$ & $\begin{array}{l}488 \\
2.60\end{array}$ & $\begin{array}{l}492 \\
3.65\end{array}$ & $\begin{array}{l}511 \\
1.56\end{array}$ & $\begin{array}{l}444 \\
2.08\end{array}$ & $\begin{array}{l}477 \\
2.60\end{array}$ & $\begin{array}{l}457 \\
4.69\end{array}$ & $\begin{array}{l}503 \\
2.60\end{array}$ & $\begin{array}{l}446 \\
3.13\end{array}$ & $\begin{array}{c}466 \\
.00\end{array}$ & $\begin{array}{l}461 \\
2.08\end{array}$ & $\begin{array}{l}523 \\
3.13\end{array}$ & $\begin{array}{l}434 \\
3.13\end{array}$ & $\begin{array}{l}476 \\
3.13\end{array}$ \\
\hline 4 & $\begin{array}{l}\text { RT } \\
\text { Percent }\end{array}$ & $\begin{array}{l}555 \\
2.60\end{array}$ & $\begin{array}{l}584 \\
2.08\end{array}$ & $\begin{array}{l}513 \\
6.22\end{array}$ & $\begin{array}{l}523 \\
2.08\end{array}$ & $\begin{array}{l}491 \\
3.65\end{array}$ & $\begin{array}{l}533 \\
3.65\end{array}$ & $\begin{array}{l}470 \\
5.21\end{array}$ & $\begin{array}{l}491 \\
2.60\end{array}$ & $\begin{array}{l}483 \\
3.13\end{array}$ & $\begin{array}{l}527 \\
7.29\end{array}$ & $\begin{array}{l}437 \\
5.21\end{array}$ & $\begin{array}{l}471 \\
2.08\end{array}$ & $\begin{array}{l}474 \\
1.56\end{array}$ & $\begin{array}{l}516 \\
2.60\end{array}$ & $\begin{array}{l}452 \\
3.13\end{array}$ & $\begin{array}{l}483 \\
2.08\end{array}$ \\
\hline
\end{tabular}




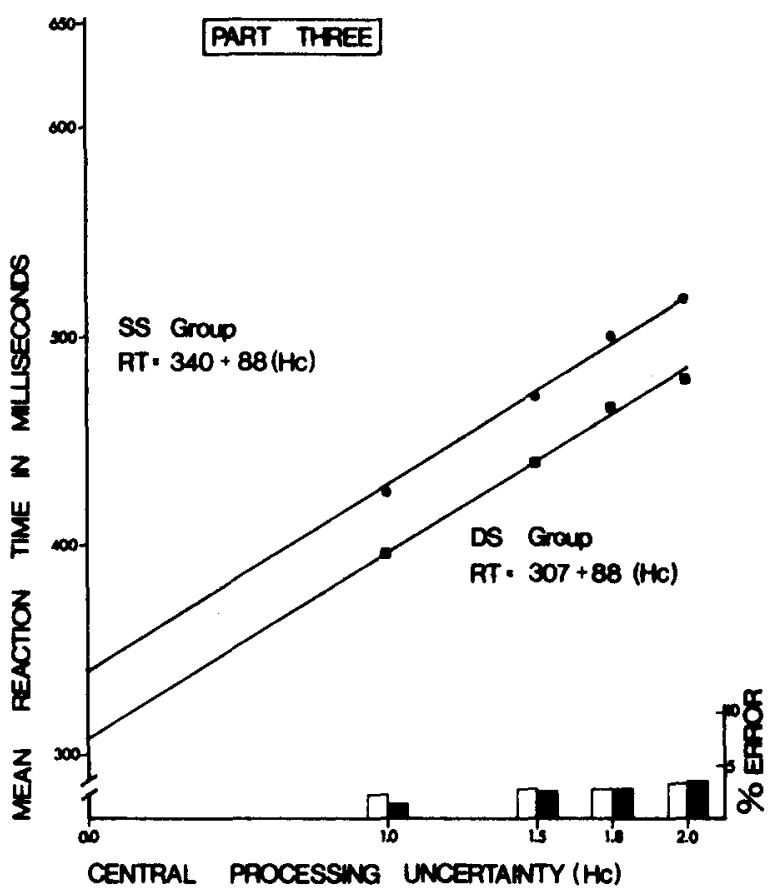

Figure 2. Parallel lines fit to the SS and DS groups using Hc (measured in bits) as the basic predictor variable in Part 3 (transfer). Error percentage is indicated by the empty columns for the SS group and by the filled columns for the DS group. The yes and no responses are combined.

interactions involving the groups factor, except for a Groups by Blocks interaction, $F(3,90)=3.96, p<.025$. Further consideration of this interaction indicated that the DS group made more errors than the SS group only in the first block of transfer. Since the SS group was also slower than the DS group in Blocks $24, t(30)=2.20$, $\mathrm{p}<.05$, it seems unlikely that the DS group's lower RT was due to subject's sacrificing their accuracy in order to increase their speed.

Consistent with the results of Part 1, a decrease in slopes $\mathrm{F}(3,93)=4.42, \mathrm{p}<.01$, but not in intercepts, $F(3,93)=.97, p>.10$ over blocks of practice was responsible for the Blocks by Positive Set Size interaction, (see Table 3). Also consistent with Part 1, the Response by Blocks interaction revealed a shift in the difference between the speed of the yes and no responses over blocks of practice. Although the yes responses were consistently faster than the no responses across the four blocks of trials, the difference between the two types of responses increased from $21 \mathrm{msec}$ in Block 1 to $45 \mathrm{msec}$ in Block 4.

Finally, it should be noted that the slope values in the DS group were significantly different from zero in the last block of Parts 1 and $3, \mathrm{t}(62)=5.12,6.12$, respectively; $\mathrm{p}<.001$ in both cases. Apparently, considerably more practice is necessary than provided in this experiment for the slopes to be reduced to values which are not significantly different from zero.

\section{DISCUSSION}

The purpose of Part 1 of this experiment was to localize the effect of a distinguishing feature in one or more stages of information processing in a memory search task. The fact that the groups and positive set size factors interacted to produce slope, but not intercept, differences between the SS and DS groups indicates that the availability of a distinguishing feature was instrumental in reducing the time required for memory search, but not the time required to extract or encode test stimulus information.

There are several possible ways that a distinguishing feature might be used to facilitate memory search. One possibility is that it might be used to eliminate the necessity of searching memory altogether. Assuming that it is possible to distinguish the positive from the negative set forms on the basis of information specifying number of sides (Owen \& Brown, 1970), and that information about the negative set and its relationship to the positive set can be used by subjects, then a decision could be made without actually searching memory. This could be achieved by extracting information specifying number of sides from the test form and directly comparing it against a memorial representation of similar information common to all of the forms in the positive set. The fact that the slope for the DS group was significantly greater than zero even after eight blocks of practice suggests that memory search was not entirely eliminated. Apparently, just testing for characteristics of the set of memorized forms is not a completely reliable basis for a decision unless the positive and negative set forms are highly distinctive or a great deal of practice and perceptual learning has taken place. For example, memory search appeared to be eliminated in the Yonas and Gibson (1967) experiment, but only after considerably more practice and opportunity for perceptual learning than was provided in Part 1 of the present experiment.

Another way that a distinguishing feature might facilitate memory search is that testing for the information characterizing the set of memorized forms might be used to influence the speed with which individual forms are examined in memory. When information is available for distinguishing the positive and negative set forms (i.e., as in the DS group), then there might be a reduction in the amount of detailed processing of individual forms during memory search necessary to determine the set membership of a particular test form.

One source of evidence for the idea that memory search can be influenced by testing for the characteristics of the set of memorized items is that the difference between the yes and no judgments was less in the DS than in the SS group. This is because a no decision in the DS group might be based upon the 
outcomes of both a test of the set of memorized forms and an examination of the individual forms making up the set.

Although detailed processing of the individual negative set forms may have been reduced in the DS group, the subjects' ability to recognize them subsequently in a forced-choice recognition task (Part 2) did not appear to be impaired relative to the SS group. The only reliable difference between the two groups was that the SS group had greater confidence in their correct recognitions than the DS group. This finding generally supports the results obtained by Yonas (1969) and Schapiro (1970). These investigators failed to obtain a difference in the retention of nontarget letters between conditions in which a feature was available for distinguishing target and nontarget items and conditions in which it was not available. Perhaps a great deal more practice is necessary before the features of individual forms are completely ignored and decisions are based entirely upon the characteristics of the set of memorized items. It is also possible that the negative set items were treated as an undifferentiated unit by both groups due to the fact that the positive and negative set items did not overlap for either group.

The fact that RT was a linear function of $\log _{2}$ of the positive set size for the SS and DS groups in both parts of this experiment appears to conflict with a large number of experiments (e.g., Bracey, 1969; Kristofferson, 1972; Sternberg, 1967, 1969) in which linear relationships have been obtained. Swanson and Briggs (1971), Briggs and Johnsen (1972), and Simpson (1972) have attributed the difference between log and linear functions to differences in the construction of the positive and negative sets. These investigators found that $\log$ relationships are obtained when the positive and negative sets are permanently fixed so that items appearing in the positive set never appear in the negative set, and vice versa. According to Swanson and Briggs (1971) and Briggs and Johnsen (1972), nonoverlapping positive and negative sets allow the negative set to be treated as an undifferentiated unit by the subject.

The assumption of an undifferentiated negative set has been used by Briggs and his colleagues (e.g., Briggs \& Johnsen, 1972; Swanson \& Briggs, 1969) in calculating $\mathrm{Hc}$ for the case of permanently fixed positive and negative sets. It allows the probability of a nonmatch to remain constant at .500 with changes in the probability of a match from .500 when the positive set size is one to, for example, .125 when the positive set size is four (see Note 1). In addition, the assumption of an undifferentiated negative set suggests that the shape of the functions that relate RT to positive set size are dependent upon the characteristics of the negative as well as the positive set.

The role of the negative set in memory search tasks is illustrated in the present experiment. First, log relationships between RT and positive set size were obtained in both groups, as would be expected from the use of nonoverlapping positive and negative set construction. Second, increasing the discriminability of the positive set forms relative to the negative set in the DS group resulted in a facilitation of memory search.

One unexpected finding in this experiment was that the slopes, but not the intercepts of the SS and DS group decreased with practice. This was surprising, because a number of investigators (e.g., Kristofferson, 1972; Ross, 1970; Sternberg, 1967; and Simpson, 1972) have found that the intercept or both the slope and intercept decrease with practice.

A possible basis for this discrepancy might be found by considering the fact that highly familiar symbols (i.e., letters and digits) with readily available verbal labels were used by all of the investigators reporting intercept or both slope and intercept changes with practice. Briggs and Blaha (1969) used unfamiliar stimuli (random forms), but they obtained intercept as well as slope changes with practice. It should be noted, however, that Briggs and Blaha (1969) required their subjects to learn verbal labels (digits) as responses to the random forms prior to the beginning of their experiment. Since there was no deliberate attempt to encourage the subjects to attach verbal labels to the random forms used in the present experiment, it is possible that the absence of an intercept change with practice reflects the subjects' ability to readily extract visual information from the test stimulus without being required to learn to ignore its verbal representation. An argument against this interpretation is Lyons and Briggs's (1971) finding that slope, but not intercept, differences are obtained when letters and random forms are compared as stimuli. These investigators did not examine practice effects, however, so it is not known whether additional practice would decrease the intercept or both the slope and intercept in the letter condition, but only decrease the slope in the random form condition.

The use of a frequency detection strategy early in practice might be used to account for the fact that the no responses were actually faster than the yes responses for both groups in the first block of practice and for the fact that the difference in favor of faster yes responses increased from the second block. In the first block of practice, the subjects were unfamiliar with both the positive and negative sets. Their degree of unfamiliarity with the negative set was probably greater, however, because there were not any repetitions of the forms until block two due to the large size of the negative set ( 48 forms). Accordingly, a subject could reject a negative set form very rapidly, particularily in the first block, because he is more certain that it is unfamiliar. As the subject acquires more experience with forms over blocks, he becomes much more familiar with the positive than the negative set forms due to their more frequent appearance and he is able to respond to the positive set forms more rapidly. 
The results of Part 3 (transfer) reveal some similarities with the results of Part 1 . Mean reaction time was again a linear function of $\log _{2}$ of the positive set size and the Blocks by Positive Set Size interaction again appeared to be accounted for by a reduction in slope, but not intercept values. In addition, although the no responses were never faster then the yes responses, the difference between them increased over blocks of practice as they had in Part 1.

The major difference between the results of Part 3 and Part 1 was the failure to obtain a significant Groups by Positive Set Size interaction. Applying the logic of Sternberg's (1969) additive factor method, this finding indicates that previous experience with a distinguishing feature does not influence memory search, but rather stages of processing which precede (information extraction or encoding) or follow (response selection) memory search. Assuming that response selection processes are not involved because only a binary decision was required, information extraction would appear to be the locus of the transfer effect.

The major finding to be accounted for then is why intercept, but not slope differences were obtained in Part 3 and why slope, but not intercept differences were obtained in Part 1? It would appear that the similarity of the slopes in Part 3 can be accounted for by the same considerations that were proposed to account for the differences in slopes in Part 1. If, as argued in Part 1, the locus of the effect of a distinguishing feature is in the memory search stage, then both the SS and DS groups should be equally facilitated in memory search by a distinguishing feature when, as in Part 3, the information available to both groups is identical.

The question is why there is an intercept difference in Part 3 is more difficult to account for. One possibility is suggested by the search model proposed to account for the Part 1 results in which information about the set of memorized forms is used as well as information about individual forms. In order for these two sources of information to interact successfully to facilitate memory search, information about the characteristics of individual items must be extracted from the test form as well as more abstract information concerning the relationship of the test form to the set of positive and negative forms. In Part 1, the extraction of both kinds of information from a test form appears to proceed at the same rate for both the SS and DS groups as indicated by the nonsignificant difference in their intercepts.

In Part 3 (transfer) new positive and negative set forms were given to both groups. Although the detailed information specifying individual forms was changed in Part 3, the abstract information which specified the number of sides of a form was not changed. Given this analysis of the availability of information to the two groups in Part 3, it is proposed that the rate of information extraction would be faster for the DS group because, unlike the SS group, the DS group had learned in Part 1 to extract more efficiently the information specifying number of sides from the test form. It is assumed, therefore, that the RT difference between the SS and DS group is primarily determined by the rate with which information specifying number of sides is extracted, and not by the rate with which information critical for distinguishing among individual forms is extracted. The latter is assumed to be equivalent for both groups.

The transfer effect obtained in Part 3 can be interpreted as an instance of perceptual learning (Gibson, 1969; Yonas, 1969). Subjects apparently learned to extract information efficiently and economically from the test forms which was useful for distinguishing between the positive and negative sets. The fact that the transfer effect was indicated by a difference in intercepts does not necessarily mean that perceptual learning effects will always be localized in the information extraction or encoding stage of information processing in a memory search task. It is possible, for example, that by using positive and negative set items that are more difficult to discriminate from each other, (e.g., 8- vs. 12-sided forms) transfer effects might be observed to influence the slope as well as the intercept. It is also possible, however, that the additive factor method is not completely adequate to represent the subject's use of information in a memory search task.

\section{REFERENCES}

Attneave, F., \& Arnoult, M. D. The quantiative study of shape and pattern perception. Psychological Bulletin, 1956, 53, 452-471.

Bracey, G. W. Two operations in character recognition: A partial replication. Perception \& Psychophysics, 1969, 6, 357-360.

Briggs, G. E. The additivity principle in choice reaction time-a functionalist approach to mental processes. In J. F. Voss and R. F. Thompson (Eds.) Topics in learning and performance. New York: Academic Press, 1972, 1-16.

Briggs, G. E., \& Blaha, J. Memory retrieval and central comparison times in information processing. Journal of Experimental Pscyhology, 1969, 79, 395-402.

Briggs, G. E., \& Swanson, J. M. Encoding, decoding and central functions in human information processing. Journal of Experimental Psychology, 1970, 86, 296-308.

Briggs, G. E., \& Johnsen, A. $\dot{M}$. On the nature of central processing in choice reactions. Memory \& Cognition, 1973, 1 , 91-100.

Draper, N. R., \& Smith, H. Applied regression analysis. New York: Wiley, 1966.

Gibson, E. J. Principles of perceptual learning and development. New York: Appleton-Century-Crofts, 1969.

Kristofferson, M. W. Effects of practice on character-classification performance. Canadian Journal of Psychology, 1972, 26, 54-60.

Lyons, J. J., \& Briggs, G. E. Speed-Accuracy trade-off with different types of stimuli. Journal of Experimental Psy chology, 1971, 91, 115-119.

Owen, D. H., \& Brown, D. R. Visual and tactual form complexity: A psychophysical approach to perceptual equivalence. Perception \& Psychophysics, 1970, 7, 225-228.

Ross, J. Extended practice with a single character classification task. Perception \& Psychophysics, 1970, 8, 276-278.

Schapiro, F. H. Information extraction and filtering during perceptual learning in visual search. Unpublished doctoral dissertation, Comell University, 1970.

Shepard, R. N. Recognition memory for words, sentences and pictures. Journal of Verbal Learning and Verbal Behavior,
$1967,6,156-163$.

Simpson, P. J, High-speed memory scanning: Stability and 
generality. Journal of Experimental Psychology, 1972, 96, 239-246.

Sternberg, $S$. Two operations in character recognition: Some evidence from reaction time experiments. Perception \& Psychophysics, 1967, 2, 45-53.

Sternberg. S. The discovery of processing stages: Extension of Donders' method. Acta Psychologica, 1969, 30, 276-315.

Swanson, J. M.. \& Briggs, G. E. Information processing as a function of speed versus accuracy. Journal of Experimental Psychology, 1969, 81, 223-229.

Yonas. A. Acquisition of information processing strategies in a time dependent task. Unpublished doctoral dissertation. Cornell University, 1969.

\section{REFERENCE NOTES}

1. Swanson, J. M., \& Briggs, G. E. The neglected negative set. Paper presented at the Midwestern Psychological Association, Detroit, 1971.

2. Yonas, A., \& Gibson, E. J. A developmental study of feature-processing strategies in letter discrimination. Paper presented at the Eastem Psychological Association, Boston, 1967.

\section{NOTE}

1. Hc is an index of the number of comparisons or tests required to determine the set membership of a test item.
Swanson and Briggs (1969) and Briggs and Swanson (1970) defined He as

$$
-\sum_{i=1}^{n} \text { pi log pi, }
$$

where $\mathrm{pi}$ is the probability of occurence of the $\mathrm{i}^{\text {th }}$ possible outcome of central processing summed overall possible $n$ outcomes. Memory load (M) provides the major contribution to the number outcomes because $n-1$ of these outcomes involves a match of the test stimulus with one of the positive set items in memory, while the remaining outcome is a nonmatch. The probability of obtaining a match between a test stimulus and a memorized item is $p=.500$ when $M=1, p=.250$ when $M=2$, $p=.167$ when $M=3$, and $p=.125$ when $M=4$. The probability of a nonmatch is $p=.500$ across all four levels of $M$. When the probabilities of matches and nonmatches were entered into the equation, the resulting values of $\mathrm{Hc}$ were $1.00(\mathrm{M}=1), 1.50$ $(M=2), 1.80(M=3)$, and $2.00(M=4)$ bits.

(Received for publication August 20, 1974; revision accepted September 6,1974 ) 